\title{
Relation of left ventricular isovolumic relaxation time and incoordination to transmitral Doppler filling patterns
}

\author{
Stephen J D Brecker, Chiang H Lee, Derek G Gibson
}

Abstract

Objective-To investigate factors during isovolumic relaxation that determine Doppler filling patterns in patients with left ventricular disease, and thus to identify the underlying mechanisms.

Design-85 patients $(50$ ischaemic heart disease, 35 left ventricular hypertrophy due to aortic stenosis) and 26 controls were studied with Doppler and $M$ mode echocardiography and phonocardiography. 16 patients underwent two studies on separate occasions, to find whether changes in isovolumic relaxation time were reflected by a change in the Doppler $\mathrm{A} / \mathrm{E}$ ratio.

Setting-A tertiary cardiac referral centre.

Subjects-Patients referred for assessment of coronary artery disease or aortic stenosis with left ventricular hypertrophy.

Main outcomes measures-Doppler filling velocities during early ( $E$ wave) and late ( $A$ wave) diastole and the $A / E$ ratio, acceleration of the $E$ wave, digitised $M$ mode indices of incoordinate relaxation (change in cavity dimension before mitral valve opening and time from minimum dimension to mitral valve opening), isovolumic relaxation time, $M$ mode measures of diastolic function after mitral valve opening (peak rate of posterior wall thinning and peak rate of dimension increase), and left ventricular end diastolic pressure.

Results-A/E correlated with age in normal subjects $(r=0.74)$, to a lesser extent in left ventricular hypertrophy $(r=0.41)$, but not significantly in ischaemic heart disease. In all patients, isovolumic relaxation time was significantly and negatively correlated with the acceleration of the $E$ wave, showing its fundamental relation to the force responsible for early diastolic filling $(r=-0.71$ for left ventricular hypertrophy, and -0.74 for ischaemic heart disease, $p$ value $<0.01)$. In left ventricular hypertrophy and those ischaemic patients without left ventricular dilatation $A / E$ was correlated both with isovolumic relaxation time $(r=0.68$ and 0.60 respectively), and with incoordinate relaxation $(r=0.65$ and 0.61 ). In those ischaemic patients with left ventricular dilatation, the influence of incoordination was lost and isovolumic relaxation time became the dominant influence upon $A / E$ $(r=0.82)$. Weak correlations of end diastolic pressure and RR interval with $A / E$, became insignificant once isovolumic relaxation time had been taken into account. Isovolumic relaxation time and incoordination together accounted for over $50 \%$ of the variance in the $A / E$ ratio in our patients. Isovolumic relaxation time and the $A / E$ ratio were linearly related. Patients with a short isovolumic relaxation time had evidence of considerable diastolic abnormalities, despite a normal Doppler A/E ratio. In the 16 patients who had two echocardiographic studies, changes in the duration of isovolumic relaxation were accompanied by a change in the Doppler A/E ratio. The relation between these two variables, derived from the group as a whole was similar.

Conclusions-The main factors influencing the $A / E$ ratio in patients with left ventricular disease are two distinct properties of isovolumic relaxationnamely the duration and the extent of incoordinate wall motion. Filling pressure and $R R$ interval are not significant independent determinants, but act only through an effect upon isovolumic relaxation time. Age is an important influence in normal people, but this effect is attenuated in left ventricular hypertrophy and lost in ischaemic ventricular disease.

\section{(Br Heart J 1992;68:567-73)}

The pattern of diastolic inflow into the ventricle can be conveniently studied with pulsed Doppler echocardiography, and the ratio of peak atrial to early diastolic velocities $(\mathrm{A} / \mathrm{E}$ ratio) has been used by many as an index of underlying left ventricular diastolic disease. ${ }^{12}$ Yet the precise mechanisms responsible for filling are complex and incompletely understood. In normal individuals, age is well recognised to be the primary determinant of the $A / E$ ratio, ${ }^{3-5}$ although in disease states it is likely that this effect will be attenuated by other overriding factors. As blood flow velocity is a function of transmitral pressure gradient, relations with left atrial or left ventricular end diastolic pressure have been sought and not surprisingly have been found. In different studies, however, the correlation of the early filling velocity and $\mathrm{E} /$ A with filling pressure, has been reported to be positive, ${ }^{6-8}$ negative, ${ }^{9}$ and non-existent, ${ }^{10}$ 
although striking changes in filling velocities due to acute alteration of loading conditions have been documented both in animals, ${ }^{11}$ and patients. ${ }^{12}{ }^{13}$ Disturbances of the $A / E$ ratio and peak rapid filling velocity have been ascribed to abnormal relaxation, ${ }^{14-16}$ as well as to reduced atrial and ventricular compliance, ${ }^{217} 18$ whereas $M$ mode studies have shown that in left ventricular hypertrophy, the $\mathrm{A} / \mathrm{E}$ ratio may be normal in the presence of obvious diastolic disease. ${ }^{19}$ Our study is based on previous findings that the duration of isovolumic relaxation or the rate of left ventricular pressure decline may affect early diastolic filling velocity in patients with left ventricular hypertrophy ${ }^{19} 20$ or ischaemic heart disease..$^{21}$ It was our aim to assess the extent to which filling velocities depended on events occurring before mitral valve opening, to identify the factors during isovolumic relaxation that might be responsible, and thus to gain insight into underlying mechanisms.

\section{Patients and Methods}

STUDY POPULATION

We studied 50 patients ( 42 men, eight women, mean age (range) 59 (37-81) years) with ischaemic heart disease, 35 patients with left ventricular hypertrophy secondary to aortic stenosis ( 20 men, 15 women, mean age 56 (14 82) years), and a control group of 26 healthy individuals ( $18 \mathrm{men}$, eight women, mean age 49 $(20-82)$ years). All patients had been referred for echocardiographic evaluation of ventricular function. Cardiac catheterisation and measurement of end diastolic pressure were carried out in 52 patients as part of their routine assessment.

\section{MODE AND CROSS SECTIONAL ECHOCARDIOGRAPHY}

$M$ mode and cross sectional echocardiograms with an Advanced Technical Laboratory Imager $\mathrm{Mk} 300 \mathrm{I}$ with a $3.0 \mathrm{MHz}$ mechanical transducer, or a Toshiba SSH 160A imager with a $3.5 \mathrm{MHz}$ transducer were taken with the patient in the standard left lateral position. Phonocardiograms were recorded with a Leatham microphone with a low frequency filter. $M$ mode echocardiograms were recorded with simultaneous eletrocardiogram and phonocardiogram, on a Honeywell (Ecoline 22) strip chart recorder at a paper speed of $10 \mathrm{~cm} / \mathrm{s}$. Only records showing clear continuous echoes from the septum and posterior wall and clear mitral cusp separation were used. Aortic valve closure $\left(A_{2}\right)$ was taken as the start of the first high frequency vibration of the aortic component of the second heart sound recorded on the phonocardiogram, and was checked for validity with the aortic echogram and the aortic closure artefact on the Doppler recordings. Left ventricular internal cavity dimensions were measured at end systole $\left(\mathrm{A}_{2}\right)$ and end diastole (start of the QRS complex on the electrocardiogram) with leading edge method, from the parasternal long axis view. Isovolumic relaxation time was measured from $\mathrm{A}_{2}$ to the initial separation of the mitral cusps on the $M$ mode echogram. All measurements were made on three cardiac cycles and the mean taken. $M$ mode echocardiograms were digitised with a Terminal Display Systems TDS 20 digitising tablet as previously described. ${ }^{22}$ Measures of incoordinate relaxation were taken as the increase in transverse cavity dimension during isovolumic relaxation expressed as a percentage of the total dimension change during the cardiac cycle, and the time interval from minimum cavity dimension to mitral valve opening. The peak rate of dimension increase $(\mathrm{dD} / \mathrm{dt})$, and the peak rate of posterior wall thinning $(\mathrm{dW} / \mathrm{dt})$ were also derived from the digitised traces. Once again, all measurements were made on three cardiac cycles, and the mean taken.

\section{DOPPLER ECHOCARDIOGRAPHY}

We recorded Doppler signals with a Doptek Spectrascan and a $2.0 \mathrm{MHz}$ transducer, and a Toshiba SSH $160 \mathrm{~A}$ with a $3.5 \mathrm{MHz}$ transducer. Peak transmitral flow velocities were identified by continuous wave from the apex, and were recorded in pulsed mode with a $3 \mathrm{~mm}$ gate, and $250 \mathrm{MHz}$ wall filter. The peak velocities of early $E$ wave and atrial $A$ wave transmitral flow were recorded and the $\mathrm{A} / \mathrm{E}$ ratio was calculated. The time from onset of early transmitral flow to the peak velocity was taken as acceleration time, and the peak velocity divided by acceleration time as early diastolic acceleration. The time interval of aortic closure to the onset of transmitral flow was also recorded. Records were taken with simultaneous electrocardiogram and phonocardiogram at a paper speed of $10 \mathrm{~cm} / \mathrm{s}$. All measurements were made on three cardiac cycles and the mean taken.

\section{CARDIAC CATHETERISATION}

52 patients from the two study groups underwent cardiac catheterisation as part of their routine assessment, from either the brachial or femoral approach. Pressure was recorded before left ventricular angiography with a fluid filled 7 or 8 French pigtail catheter attached to a manifold micromanometer transducer (Medex Medical), with zero taken at mid-chest level. The left ventricular end diastolic pressure was measured at the point on the pressure waveform corresponding to the onset of the QRS complex on the electrocardiogram. The mean of 10 cardiac cycles was recorded. All studies were performed within 48 hours of the echocardiographic examination.

\section{STATISTICAL ANALYSIS}

All values are given as mean (SD). Differences between mean values were compared by Student's $t$ test. Simple and stepwise regression, multiple regression, and linear correlation were performed to assess relation between variables.

\section{Results}

\section{GROUP CHARACTERISTICS}

Table 1 summarises the description and comparison of the subjects. The patients with ischaemic heart disease were older than the normal subjects, but no other significant dif- 
Table 1 Characteristics of the groups (mean (SD))

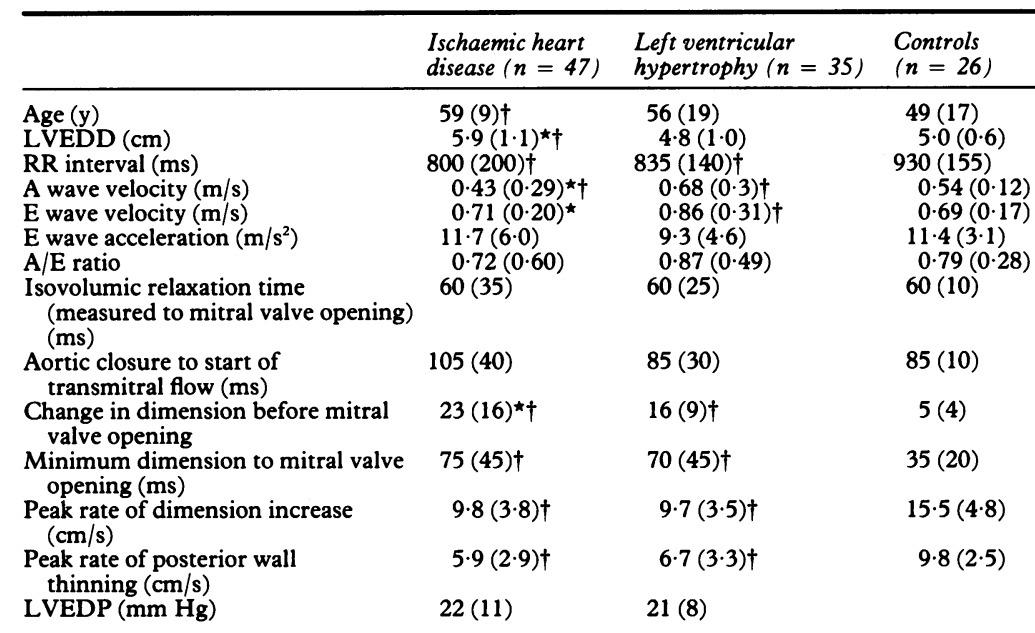

LVEDD, left ventricular end diastolic dimension; LVEDP, left ventricular end diastolic pressure; ${ }^{\star} \mathrm{p}<0.05 v$ group with left ventricular hypertrophy; $\nmid \mathrm{p}<0.05 v$ controls.

ferences existed with respect to age. Left ventricular end diastolic dimension was greater in patients with ischaemic heart disease (5.9 $(1 \cdot 1) \mathrm{cm})$ than both those with left ventricular hypertrophy $(4.8(1.0))$ and the controls $(5 \cdot 0$ $(0 \cdot 6))$. The RR interval was significantly shorter in both patient groups compared with controls $(800(200) \mathrm{ms}$ and 835 (140) v 930 (155)). These differences did not affect within group analysis.

The mean value for peak $E$ wave velocity was greater in patients with left ventricular hypertrophy than in both other groups $(0.86(0.31) v$ $0.71(0.20)$ and $0.69(0.17) \mathrm{m} / \mathrm{s})$, in whom the mean value did not differ significantly. The mean value for peak $A$ wave velocity was also greater in patients with left ventricular hypertrophy than in the controls $(0.68(0.3) v 0.54$ $(0.12) \mathrm{m} / \mathrm{s})$ so that the $A / E$ ratio did not differ significantly $(0.87(0.49) v 0.79(0.28))$, although the SD was clearly higher, reflecting the wide range of values for the $A / E$ ratio seen in left ventricular hypertrophy. Although the A wave velocity was less in patients with ischaemic heart disease than normal $(0.43$ $(0.29) \mathrm{m} / \mathrm{s})$, once again the mean $\mathrm{A} / \mathrm{E}$ ratio did not differ significantly from normal $(0 \cdot 72(0 \cdot 60))$, the high SD similarly reflects the wide range of values seen in ischaemic heart disease. The mean value for $E$ wave acceleration in the group with left ventricular hypertrophy was not significantly lower than the other two groups.

Table 2 Subgroup analysis of the group with ischaemic disease (mean (SD))

\begin{tabular}{lcc}
\hline & $\begin{array}{c}\text { Dilated cavity } \\
(L V E D D>6 \mathrm{~cm})\end{array}$ & $\begin{array}{c}\text { Non-dilated cavity } \\
(\text { LVEDD }<6 \mathrm{~cm})\end{array}$ \\
\hline Age (y) & $56(9)^{\star}$ & $62(9) \dagger$ \\
LVEDD (cm) & $6 \cdot 8(0 \cdot 5)$ & $5 \cdot 0(0 \cdot 8)$ \\
Shortening fraction (\%) & $14 \cdot 6(4 \cdot 5)^{\star}$ & $23 \cdot 1(7 \cdot 1)$ \\
RR Interval (ms) & $765(200) \dagger$ & $840(195)$ \\
A wave velocity (m/s) & $0 \cdot 39(0 \cdot 31) \dagger$ & $0 \cdot 47(0 \cdot 29)$ \\
E wave velocity (m/s) & $0 \cdot 74(0 \cdot 17)$ & $0 \cdot 66(0 \cdot 22)$ \\
A/E ratio & $0 \cdot 57(0 \cdot 52)$ & $0 \cdot 86(0 \cdot 65)$ \\
Isovolumic relaxation time (ms) & $55(30)$ & $70(35)$ \\
Change in dimension before mitral valve opening (\%) & $21(14) \dagger$ & $25(18) \dagger$ \\
Minimum dimension to mitral valve opening (ms) & $70(40) \dagger$ & $80(45) \dagger$ \\
Peak rate of dimension increase (cm/s) & $9 \cdot 2(3 \cdot 1) \dagger$ & $10 \cdot 4(4 \cdot 3) \dagger$ \\
Peak rate of posterior wall thinning (cm/s) & $5 \cdot 5(2 \cdot 8) \dagger$ & $6 \cdot 2(3) \dagger$ \\
LVEDP (mm Hg) & $22(9)$ & $20(12)$ \\
\hline
\end{tabular}

LVEDD, left ventricular end diastolic dimension; LVEDP, left ventricular end diastolic pressure; ${ }^{\star} \mathrm{p}<0.05 v$ group with normal cavity dimension; $\dagger \mathrm{p}<0.05 v$ normal control group.
The mean values of isovolumic relaxation time seen in each group were identical (60 (35), 60 (25), 60 (10) ms), although the range of values seen in both patient groups was much wider than in the controls. The time from aortic closure to the start of flow was significantly longer than the isovolumic relaxation time measured as aortic closure to the point of mitral cusp separation in all groups. This discrepancy was $25 \mathrm{~ms}$ in left ventricular hypertrophy and normal people, and $45 \mathrm{~ms}$ in those with ischaemic heart disease. This discrepancy did not significantly differ between those ischaemic patients with and without incoordinate relaxation. In both ischaemia and hypertrophy, measures of incoordination during isovolumic relaxation were greater than in the controls, both as the percentage change in dimension before mitral valve opening, and the time interval from minimum cavity dimensions to mitral valve opening. These two measures were, as expected, highly correlated.

Peak rates of dimension increase and posterior wall thinning were significantly reduced in both patient groups compared with controls.

\section{WITHIN GROUP COMPARISON}

Cavity size

To investigate the effect of cavity dilatation, we divided patients with ischaemic heart disease into two groups according to the end diastolic dimension. Those with left ventricular dilatation were younger and with a significantly reduced shortening fraction, but there were no other significant differences between the two groups in terms of Doppler or $M$ mode indices of diastolic function. Indices of diastolic function in both subgroups were significantly different from normal (table 2).

\section{Isovolumic relaxation}

Figure 1 shows that the isovolumic relaxation time and the Doppler A/E ratio for all patients with left ventricular disease were linearly related. When subdivided into two groups depending on isovolumic relaxation time, those with shorter values had significantly less incoordination and a greater peak rate of dimension increase. Importantly however, both subgroups had $M$ mode indices of diastolic function that were significantly different from normal (table 3).

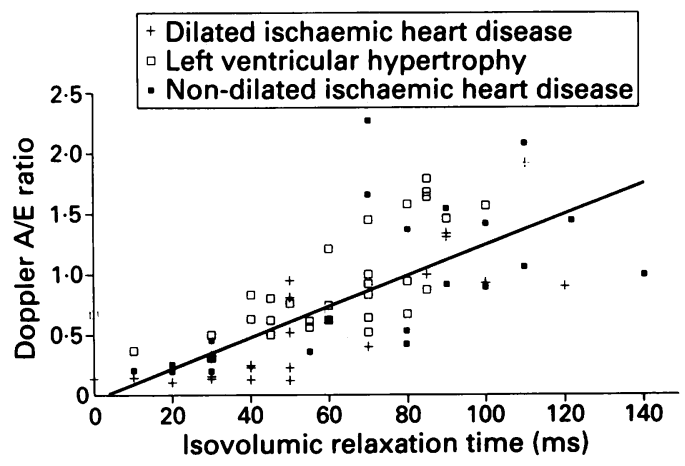

Figure 1 Relation between Doppler $A / E$ ratio and isovolumic relaxation time for all three patient groups. The three regression lines were so similar that they are represented by a single line. 
Table 3 Subgroup analysis of all patients with left ventricular disease, based upon isovolumic relaxation time (mean (SD))

\begin{tabular}{lll}
\hline Variable & $I V R T<60 \mathrm{~ms}$ & IVRT $>60 \mathrm{~ms}$ \\
\hline Isovolumic relaxation time (ms) & $40(15)$ & $90(20)$ \\
Change in dimension before mitral valve opening (\%) & $15(11)^{\star} \dagger$ & $27(15)^{\star}$ \\
Minimum dimension to mitral valve opening (ms) & $55(35)^{\star \dagger}$ & $90(40)^{\star}$ \\
Peak rate of dimension increase (cm/s) & $10 \cdot 8(3 \cdot 6)^{\star} \dagger$ & $8 \cdot 7(3.5)^{\star}$ \\
Peak rate of posterior wall thinning (cm/s) & $6 \cdot 8(3 \cdot 3)^{\star}$ & $5 \cdot 7(2 \cdot 8)^{\star}$ \\
LVEDP (mm Hg) & $23(9)$ & $19(9)$ \\
\hline
\end{tabular}

IVRT, isovolumic relaxation time; LVEDP, left ventricular end diastolic pressure; ${ }^{\star} p<0.05$ normal control subjects; $\nmid \mathrm{p}<0.05 v$ group with IVRT $>60 \mathrm{~ms}$.

Effect of age on filling pattern

A/E correlated with age in normal individuals $(r=0.74)$, to a lesser extent in those with left ventricular hypertrophy $(r=0.41)$, but not significantly in those with ischaemic heart disease (table 4).

\section{SEPARATE EFFECTS OF ISOVOLUMIC RELAXATION TIME AND INCOORDINATION UPON FILLING PATTERN}

In left ventricular hypertrophy and those ischaemic patients without left ventricular dilatation, $\mathrm{A} / \mathrm{E}$ was correlated both with isovolumic relaxation time $(r=0.68$ and 0.60 respectively), and with incoordinate relaxation (measured as a percentage change before mitral valve opening, $r=0.65$ and 0.61 , table 4). In those ischaemic patients with left ventricular dilatation (end diastolic dimension $>6 \mathrm{~cm}$ ), the influence of incoordination was lost and isovolumic relaxation time became the dominant influence upon $\mathrm{A} / \mathrm{E}(r=0.82)$. This was despite considerable incoordinate relaxation being evident in this subgroup. Stepwise regression confirmed that weak correlations of end diastolic pressure and $R R$ interval with $\mathrm{A} / \mathrm{E}$ became insignificant once isovolumic relaxation time had been taken into account. Multiple regression analysis for the group with ischaemic heart disease, and that with left ventricular hypertrophy, showed that isovolumic relaxation time (IVRT) and incoordinate relaxation account for over $50 \%$ of the variance in the Doppler $\mathrm{A} / \mathrm{E}$ ratio.

In patients with ischaemic heart diseases, the regression equation was:

$\mathrm{A} / \mathrm{E}=-0.128+0.011$ IVRT $+0.009 \%$ change before mitral valve opening;

$$
\mathrm{R}^{2}=52 \%
$$

In left ventricular hypertrophy, it was:

$\mathrm{A} / \mathrm{E}=-0.095+0.011$ IVRT $+0.017 \%$ change before mitral valve opening;

$$
\mathrm{R}^{2}=60 \%
$$

\begin{tabular}{|c|c|c|c|c|}
\hline & Controls & $\begin{array}{l}\text { Left } \\
\text { ventricular } \\
\text { hypertrophy }\end{array}$ & $\begin{array}{l}\text { Ischaemic } \\
\text { heart disease } \\
\text { non-dilated }\end{array}$ & $\begin{array}{l}\text { Ischaemic } \\
\text { heart disease } \\
\text { dilated }\end{array}$ \\
\hline $\begin{array}{l}\text { Age } \\
\text { Isovolumic relaxation time }\end{array}$ & $\begin{array}{l}0 \cdot 74^{\star \star} \\
0 \cdot 04\end{array}$ & $\begin{array}{l}0 \cdot 41^{\star} \\
0 \cdot 68^{\star \star}\end{array}$ & $\begin{array}{l}0.28 \\
0 \cdot 60^{\star \star}\end{array}$ & $\begin{array}{l}0 \cdot 23 \\
0 \cdot 82^{\star \star}\end{array}$ \\
\hline \multicolumn{5}{|l|}{ Incoordinate relaxation: } \\
\hline Change in dimension before mitra & $10 \cdot 25$ & $0.65^{\star \star}$ & $0 \cdot 61^{\star \star}$ & $0 \cdot 27$ \\
\hline $\begin{array}{l}\text { Minimum dimension to mitral } \\
\text { valve }\end{array}$ & $0 \cdot 15$ & $0 \cdot 72^{\star \star}$ & $0 \cdot 50^{\star \star}$ & $0 \cdot 22$ \\
\hline $\begin{array}{l}\text { opening }(\mathrm{ms}) \\
\text { RR Interval } \\
\text { LVEDP }\end{array}$ & 0.02 & $\begin{array}{c}0 \cdot 17 \\
-0.37^{\star}\end{array}$ & $\begin{array}{c}0.09 \\
-0.48^{\star}\end{array}$ & $\begin{aligned} & 0 \cdot 54^{\star \star} \\
- & 0 \cdot 2\end{aligned}$ \\
\hline
\end{tabular}

Table 4 Correlation coefficients of the $A / E$ ratio

LVEDP, left ventricular end diastolic pressure; ${ }^{\star} \mathrm{p}<0.05 ;{ }^{\star} \mathrm{p}<0.01$.

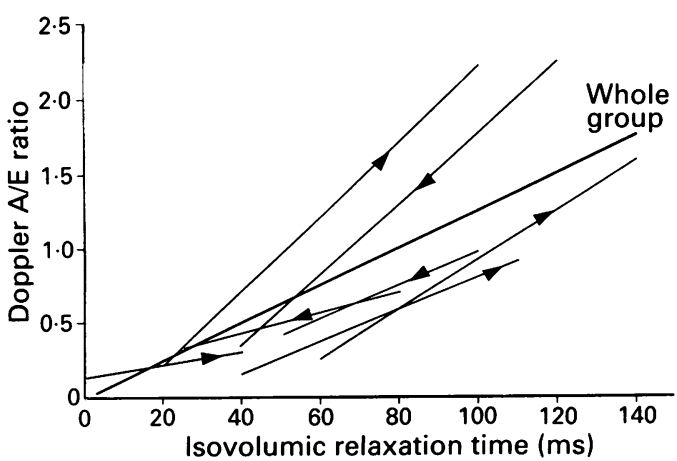

Figure 2 Results of changes in the Doppler $A / E$ ratio and isovolumic relaxation time in the seven patients studied on two occasions, with the largest changes. The arrows indicate the direction of change and the broad line represents the regression line derived from the group as a whole from fig 1 . Note that changes within individual patients behave in a similar fashion to differences between patients.

EFFECT OF ISOVOLUMIC RELAXATION TIME UPON ACCELERATION

Isovolumic relaxation time correlated significantly with acceleration of early diastolic flow in both ischaemic heart disease $(r=-0.74, \mathrm{p}<0.01)$, and left ventricular hypertrophy $(r=-0.71$, $\mathrm{p}<0.01)$.

\section{CHANGES WITHIN PATIENTS}

Sixteen patients were studied more than once, and in all cases, changes in the duration of isovolumic relaxation time were matched by a concomitant change in the Doppler $\mathrm{A} / \mathrm{E}$ ratio. The time between the two studies was 6 (5) months. Figure 2 shows the findings in the seven patients with the greatest changes. Some patients had increased isovolumic relaxation time and Doppler $\mathrm{A} / \mathrm{E}$ ratio, and conversely, those whose isovolumic relaxation time got shorter had a reduced $A / E$ ratio. Figure 3 shows the relation between the magnitude of change in isovolumic relaxation time and the magnitude of change in the $A / E$ ratio for all patients. These striking changes occurred without any evidence that the underlying diastolic properties of the left ventricle had changed (table 5).

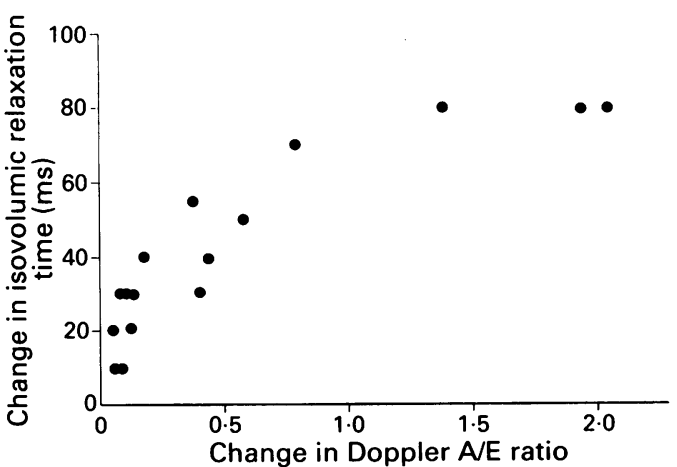

Figure 3 Relation between the size of change in the Doppler $A / E$ ratio, plotted against the size of change in isovolumic relaxation time, in the 16 patients studied on two occasions. 
Table 5 Doppler A/E ratio, isovolumic relaxation time, and indices of diastolic function in 16 patients studied on two occasions: data are presented for the lower $A / E$ ratio and higher $A / E$ ratio studies (mean $(S D)$ )

\begin{tabular}{lcc}
\hline & $\begin{array}{c}\text { Value when } A / E \text { ratio } \\
\text { was low }\end{array}$ & $\begin{array}{c}\text { Value when } A / E \text { ratio } \\
\text { was high }\end{array}$ \\
\hline A/E ratio & $0 \cdot 46(0.53)$ & $1 \cdot 01(0.53)$ \\
Isovolumic relaxation time (ms) & $40(35)^{\star}$ & $80(40)$ \\
Peak rate of dimension increase $(\mathrm{cm} / \mathrm{s})$ & $10 \cdot 6(3 \cdot 4)$ & $9 \cdot 7(4 \cdot 1)$ \\
Peak rate of posterior wall thinning $(\mathrm{cm} / \mathrm{s})$ & $8 \cdot 8(2 \cdot 3)$ & $7 \cdot 6(3.6)$ \\
\hline
\end{tabular}

${ }^{*} \mathrm{p}<0.05 v$ group with higher $\mathrm{A} / \mathrm{E}$ ratio. resolved by stepwise regression analysis, into two discrete components: isovolumic relaxation time itself and the extent of incoordination during isovolumic relaxation. Both were independently significant in patients with left ventricular hypertrophy or ischaemic heart disease with normal cavity size. We have already shown the importance of incoordination in affecting rapid filling during early diastole, ${ }^{25}$ and the results of our patients with ischaemic heart disease and normal cavity size are entirely compatible with this study. In those ischaemic patients with cavity dilatation, however, isovolumic relaxation time was the only influence upon the $\mathrm{A} / \mathrm{E}$ ratio. This was not due to a lack of incoordination in the patients with dilated ventricles; on the contrary, they had particularly incoordinate ventricles. This association between isovolumic relaxation and filling was very significant in all three patient groups with values of $R^{2}$ (and thus the proportion of overall variance of filling pattern accounted for) consistently above $50 \%$. This implies that events before rather than after mitral opening, were the dominant determinants of both the initial acceleration of blood into the left ventricle, and of the $A / E$ ratio of these patients with ventricular disease.

By definition a force is that which causes acceleration. In being so closely associated with initial acceleration, therefore, events during isovolumic relaxation must also be closely related to the forces causing blood flow from the left atrium to the ventricle-that is, to the atrioventricular pressure gradient. Several potential mechanisms exist to explain this connection. Isovolumic relaxation time itself has already been shown to be closely related to left ventricular filling pressure, ${ }^{26}$ which may partly explain our findings. This simple relation, however, would not account for the additional effect of incoordination during isovolumic relaxation. Incoordinate wall motion is due to asynchronous termination of systole in different regions of the ventricle. ${ }^{27}$ Clearly, this cannot be assessed in detail from the ventricular pressure pulse, but its overall effect is likely to slow the rate of fall of pressure, and thus to prolong isovolumic relaxation time independently of the pressure difference between the aorta and left atrium. Also, the early diastolic pressure drop across the mitral valve depends on the effective pressure within the left ventricle as well as the left atrium. Normally, left ventricular pressure in early diastole is negative to atmospheric pressure, reflecting the effect of restoring forces within the myocardium at end systole. ${ }^{28-30}$ Dissipation of these forces by incoordinate relaxation would thus increase effective ventricular pressure towards zero by the time the mitral valve opens and so reduce the atrioventricular pressure gradient independently of any change in orthodox estimates of left atrial pressure (made with respect to the atmosphere or mid right atrium). The absence of the effect of incoordination on early diastolic acceleration in patients with cavity dilatation, unlike its clear effect in the other two groups, can also be explained on this basis. We have already presented evidence flow velocity but on the peak initial acceleration of blood during early diastole. Further, the influence of isovolumic relaxation could be ischaemic heart disease as a whole, this with and without incoordination, suggesting that the primary effect of the disturbance is to delay mitral valve opening itself, rather than the start of transmitral flow once the valve has opened. In the present study we were able to 
suggesting that normal ventricular restoring forces are maintained in patients with left ventricular hypertrophy, ${ }^{31}$ but not in those with cavity dilatation and low ejection fraction. ${ }^{23}$ If restoring forces are not generated at end systole, then incoordinate wall motion during isovolumic relaxation would not be expected to have any further effect on early diastolic transmitral flow. These effects of incoordination are not easy to reproduce in any experimental model, and must thus be studied clinically.

The linear relation between the Doppler A/E ratio and isovolumic relaxation time has practical consequences. If isovolumic relaxation time is less than $60 \mathrm{~ms}$, the $\mathrm{A} / \mathrm{E}$ ratio will be normal $(<1.0)$ regardless of whether or not diastolic disease is present. We were able to show that such patients had reduced rates of dimension increase and posterior wall thinning, thus clearly dissociating filling pattern from diastolic disease. Further evidence for this dichotomy came from observations on the same patient under different circumstances when large changes in isovolumic relaxation time were accompanied by corresponding alterations in the $\mathrm{A} / \mathrm{E}$ ratio, under conditions in which the fundamental diastolic properties of the ventricle are most unlikely to have altered. Indeed no significant changes were recorded in peak rates of dimension increase or peak rates of posterior wall thinning in these patients. It is clearly important to know this when interpreting the effects of interventions: small changes in the $\mathrm{A} / \mathrm{E}$ ratio and isovolumic relaxation time have, for example, been taken as evidence of improved diastolic properties of the ventricle after angioplasty. ${ }^{32}$ These changes might well be explained in terms of simple alterations in loading conditions.

Isovolumic relaxation time has been seen as little more than a brief period between the end of ejection and the start of filling. Its physiological significance, however, is far greater than this. The relative effects of the two distinct processes we have defined, differ between patient groups. The duration of isovolumic relaxation depends on loading conditions. Superimposed on this are the effects of incoordinate wall motion that not only reduce the rate of left ventricular pressure decline, but also interfere with the transmission of restoring forces from their generation at end systole to their coupling to filling at the time of mitral valve opening. It is thus unsatisfactory to consider these events as the single entity of "relaxation" and still more so to describe them as a time constant of left ventricular pressure fall. It is now apparent that pressure fall is not exponential, even in healthy individuals. ${ }^{2933}$ When the time of onset and rate of pressure decline both vary in different regions of the ventricle, then this assumption of exponential pressure fall is still more questionable. Also, measuring it is an invasive procedure whereas the simple approach we have outlined, based on $M$ mode echocardiography and phonocardiography, is not only non-invasive, but allows both components to be determined independently.

The major diastolic function of the ventricle is to increase its volume. This process is frequently abnormal in disease, and it is important to identify and possibly treat the underlying factors. Our results clearly show that it is during isovolumic relaxation and not after mitral valve opening that the pattern of filling is determined, so that equally it is before mitral valve opening that factors governing this important process should be sought. These may be primary disturbances of isovolumic relaxation itself, or more commonly are the result of abnormal function even earlier in the cardiac cycle, ${ }^{34}{ }^{35}$ the right ventricle,${ }^{36}$ or even in activation. ${ }^{37} 38$ This approach is proving more fruitful than use of filling patterns to predict later diastolic properties such as cavity compliance, myocardial stiffness, or end diastolic pressure.

SJDB is supported by a British Heart Foundation Junior Research Fellowship. CHL was supported by the Brompton Hospital Special Cardiac Fund.

1 Nishimura RA, Abel MD, Hatle LK, Tajik AJ. Assessment of diastolic function of the heart: background and curren applications of Doppler echocardiography. Part II Clinical studies. Mayo Clin Proc 1989;64:181-204.

2 Danford DA, Huhta JC, Murphy DJ Jr. Doppler echocardiographic approaches to ventricular diastolic function. Echocardiography 1986;3:33-40

3 Miyatake K, Okamoto M, Kinoshita N, et al. Augmentation of atrial contribution to left ventricular inflow with aging as assessed by intracardiac Doppler flowmetry. Am J Cardio 1984;53:586-9.

4 Kuo LC, Quinones MA, Rokey R, Sartori M, Abinader EG, Zoghbi WA. Quantification of atrial contribution to left ventricular filling by pulsed Doppler echocardiography ventricular filling by pulsed Doppler echocardiography and the effect of age in nor

5 Bryg RJ, Williams GA, Labovitz AJ. Effect of aging on left ventricular diastolic filling in normal subjects. $A m$ Cardiol 1987;59:971-4.

6 Channer KS, Culling W, Wilde P, Jones JV. Estimation of left ventricular end-diastolic pressure by pulsed Doppler ultrasound. Lancet 1986;i:1005-7.

7 Kuecherer H, Ruffmann K, Kuebler W. Determination of left ventricular filling parameters by pulsed Doppler echocardiography: a noninvasive method to predict high filling pressures in patients with coronary artery disease. Am Heart J 1988;116:1017-21.

8 Choong CY, Herrmann HC, Weyman AE, Fifer MA Preload dependence of Doppler-derived indexes of left ventricular diastolic function in humans. $\mathrm{J} \mathrm{Am}$ Coll Cardiol 1987;10:800-8.

9 Störk TV, Müller RM, Piske GJ, Ewert CO, Hochrein H. Noninvasive measurement of left ventricular filling presNoninvasive measurement of left ventricular filling pres-
sures by means of transmitral pulsed Doppler ultrasound. Am J Cardiol 1989;64:655-60.

10 Ettles DF, Davies J, Williams GJ. Can left ventricular end diastolic pressure be estimated non-invasively? Int $J$ Cardiol 1988;20:239-45.

11 Nishimura RA, Abel MD, Hatle LK, et al. Significance of Doppler indices of diastolic filling of the left ventricle: Comparison with invasive hemodynamics in a canine model. Am Heart $J$ 1989;118:1248-58.

12 Stoddard MF, Pearson AC, Kern MJ, Ratcliff J, Mrosek DG, Labovitz AJ. Influence of alteration in preload on the pattern of left ventricular diastolic filling as assessed by Doppler echocardiography in humans. Circulation 1989;79:1226-36

13 Marino P, Destro G, Barbieri E, Zardini P. Early left ventricular filling: An approach to its multifactorial nature using a combined hemodynamic-Doppler technique. $A m$ Heart $J$ 1991;122:132-41.

14 Ishida Y, Meisner JS, Tsujioka $\mathrm{K}$, et al. Left ventricular filling dynamics: influence of left ventricular relaxation and left atrial pressure. Circulation 1986;74:187-96.

15 Choong CY, Abascal VM, Thomas JD, Guerrero JL, McGlew S, Weyman AE. Combined influence of ventricular loading and relaxation on the transmitral flow velocity profile in dogs measured by Doppler echovelocity profile in dogs measured by

16 Takagi S, Tokota $M$, Iwase $M$, et al. The important role of left ventricular relaxation and left atrial pressure in the left left ventricular relaxation and left atrial pressure in the left ventricular

17 Stoddard MF, Pearson AC, Kern MJ, Ratcliff J, Mrosek DG, Labovitz AJ. Left ventricular diastolic function Comparison of pulsed Doppler echocardiographic and hemodynamic indexes in subjects with and without coronary artery disease. J Am Coll Cardiol 1989;13:327-36.

18 Himura Y, Kumada T, Kambayashi M, et al. Importance of left ventricular systolic function in the assessment of left ventricular diastolic function with Doppler transmitra flow velocity recording. J Am Coll Cardiol 1991;18:753-60. 
19 Lee CH, Hogan JC, Gibson DG. Diastolic disease in left ventricular hypertrophy: comparison of $M$ mode and Doppler echocardiography for the assessment of rapid ventricular filling. Br Heart J 1991;65:194-200

20 Sanderson JE, Gibson DG, Brown DJ, Goodwin JF. Left ventricular filling in hypertrophic cardiomyopathy. An angiographic study. Br Heart $J$ 1977;39:661-70

21 Fioretti P, Brower RW, Meester GT, Serruys PW. Interaction of left ventricular relaxation and filling during early diastole in human subjects. Am $J$ Cardiol 1980;46: 197-203.

22 Gibson DG, Brown D. Measurement of instantaneous left ventricular dimension and filling rate in man, using echocardiography. Br Heart J 1973;35:1141-9.

$23 \mathrm{Ng} \mathrm{KSK}$, Gibson DG. Relation of filling pattern to diastolic function in severe left ventricular disease. Br Heart $J$ function in sev

24 Lee CH, Vancheri F, Josen MS, Gibson DG. Discrepancies in the measurement of isovolumic relaxation time: a study in the measurement of isovolumic relaxation time: a study
comparing $M$ mode and Doppler echocardiography. $\mathrm{Br}$ Heart $J 1990 ; 64 \cdot 214-8$

25 Hui WKK, Gibson DG. Mechanisms of reduced left ventricular filling rate in coronary artery disease. $\mathrm{Br}$ Heart $J$ 1983;50:362-71

26 Mattheos M, Shapiro E, Oldershaw PJ, Sacchetti R, Gibson DG. Non-invasive assessment of changes in left ventricular relaxation by combined phono-, echo-, and mechanocardiography. Br Heart J 1982;47:253-60.

27 Gibson DG, Prewitt TA, Brown DJ. Analysis of left ventricular wall movement during isovolumic relaxation and its relation to coronary artery disease. Br Heart $J$ 1976;38:1010-9.

28 Suga H, Goto Y, Igarashi Y, Yamada O, Nozawa T, Yasumura Y. Ventricular suction under zero source pressure for filling. Am J Physiol 1986;251:47-55.

29 Yellin EL, Hori M, Yoran C, Sonnenblick EH, Gabbay S,
Frater RWM. Left ventricular relaxation in the filling and nonfilling intact canine heart. Am J Physiol 1986;250: 620-9

30 Nikolic S, Yellin EL, Tamura K, et al. Passive properties of canine left ventricle: diastolic stiffness and restoring forces. Circ Res 1988;62:1210-22.

31 Park CH, Chow WH, Gibson DG. Phase differences between left ventricular wall motion and transmitral flow in man evidence for involvement of ventricular restoring forces in normal rapid filling. Int $J$ Cardiol 1989;24:347-54

32 Castello R, Pearson AC, Kern MJ, Labovitz AJ, Lenzen P. Diastolic function in patients undergoing coronary angioplasty: Influence of degree of revascularisation. $J$ Am Coll Cardiol 1990;15:1564-9.

33 Yellin E, Nikolic S, Frater RWM. Left ventricular filling dynamics and diastolic function. Prog Cardiovasc Dis dynamics and 1900 : $247-71$.

34 Doran JH, Traill TA, Brown DJ, Gibson DG. Detection of abnormal left ventricular wall movement during iso-
volumic contraction and early relaxation. Comparison of volumic contraction and early relaxation. Comparison of

35 Gibson DG, Doran JH, Traill TA, Brown DJ. Abnormal left ventricular wall movement during early systole in patients with angina pectoris. Br Heart $J$ 1978;40:758-66.

36 Brecker SJ, Stojnic BB, Xiao HB, Mbaissouroum M, Gibson DG. Prolonged right ventricular systole impair eft ventricular filling in pulmonary hypertension [Abstract]. J Am Coll Cardiol 1992;19 (suppl A):394.

37 Zélinsky R, Diebold B, Raffoul H, Cohen A. Modifications of the mitral flow due to the presence of a left bundle branch block (LBBB) [Abstract]. J Am Coll Cardiol 1988;11 (suppl A): 174 .

38 Xiao HB, Lee CH, Gibson DG. Effect of left bundle branch block on diastolic function in dilated cardiomyopathy. $\mathrm{Br}$ Heart $J$ 1991;66:443-7. 